\title{
Epidemiology
}

\section{e Concern about the Expanding Prescription Drug Epidemic: A Survey of Licensed Prescribers and Dispensers}

Eric R. Wright, PhD, Nia Reed, MA, Neal Carnes, MA, and Harold E. Kooreman, MA

\section{From: Department of Sociology, Georgia State University, Atlanta, GA \\ Address Correspondence: Eric R. Wright, PhD Professor \\ Sociology and Public Health Georgia State University Department of Sociology \\ Langdale Hall, Room 1061 P.O. Box 5020 Atlanta, GA 30302-5020 \\ E-mail: ewright28@gsu.edu \\ Disclaimer: There was no external funding in the preparation of this manuscript. \\ Conflict of interest: Each \\ author certifies that he or \\ she, or a member of his or her immediate family, has no commercial association (i.e., consultancies, stock ownership, equity interest, patent/licensing arrangements, etc.) that might \\ pose a conflict of interest in connection with the submitted manuscript. \\ Manuscript received: 07-06-2015 \\ Accepted for publication: 08-06-2015}

Free full manuscript: www.painphysicianjournal.com
Background: Prescription drug misuse and abuse has reached epidemic levels in the U.S., and stands as a leading cause of death. As the primary gatekeepers to the medications contributing to this epidemic, it is critical to understand the views of licensed health care professionals.

Objective: In this study, we examine health care professionals' concern regarding prescription drug abuse in their communities and the impact their concern has had on their prescribing and dispensing practices.

Study Design: An online survey of licensed health care providers.

Setting: Conducted in Indiana.

Methods: This study was a state-wide evaluation of Indiana's prescription drug monitoring program. The questionnaire asked respondents how concerned they were about prescription drug abuse in their community. Variation in the level of concern was examined using ordinary least squares regression and information about the respondents' demographic background and clinical experience. In addition, we used logistic regression to examine whether concern was associated with changing prescribing and/or dispensing behavior.

Results: The majority of providers indicated they were "moderately" or "extremely concerned" about prescription drug abuse in their communities. The level of concern, however, varied significantly by profession, with pharmacists, physicians, nurse practitioners/physician assistants being more concerned than dentists. Additional analyses indicate that providers with higher levels of concern were those who also reported recently changing their prescribing and/ or dispensing behavior.

Limitations: The voluntary nature and geographical focus of the study limits the generalizability of the findings.

Conclusion: Concern about prescription drug abuse is generally high across the major health care professions; however, a significant minority of providers, particularly among dentists, expressed little or no concern about the epidemic. Increasing health care providers' general level of concern about prescription drug abuse may be an effective public health tool for encouraging voluntary reductions in prescribing and/or dispensing controlled substances.

Key words: Attitudes of physicians, nurse practitioners, physician assistants, and dentists; prescription drug misuse and abuse; prescribing practices; dispensing practices

Pain Physician 2016; 19:E197-E208 
T he misuse and abuse of prescription drugs continue to expand in the U.S. (1-3). Over the past 2 decades, prescription drug misuse and abuse emerged as a leading cause of injury-related deaths in the U.S. (4-7). Addictive medications, including opioids, central nervous system (CNS) depressants, and stimulants are the most frequently prescribed and abused drugs $(8,9)$. The most significant impact and increase in opioid and stimulant abuse have occurred among teenagers and young adults $(10,11)$, while CNS depressants are abused more frequently by older adults and are a contributing factor in the majority of fallrelated injuries and deaths $(12,13)$. In terms of who is at inflated risk, non-Hispanic whites, males, and rural residents are more likely to abuse prescription drugs (14-16). The cost of opioid abuse in the U.S. reached nearly $\$ 56$ billion in 2007 and has likely continued to increase alongside the increase in distribution and abuse of prescription drugs (17).

To combat the expanding epidemic, public health policymakers and researchers are exploring a variety of intervention strategies. These strategies consider how to reduce the demand for prescription drugs and to contract the supply of scheduled narcotics available in communities. While public concern and awareness of the negative consequences related to prescription drug misuse and abuse has grown in recent years (18), surprisingly little is known about health care providers' attitudes regarding prescription drug abuse in their communities, or how their views influence efforts to address the epidemic. This paper summarizes data from a large survey of health care providers to fill gaps in our knowledge and improve our understanding of the policy landscape surrounding this critical public health problem.

\section{BACKGROUND}

Recent research has documented that growing rates of prescription drug misuse and abuse are strongly related to the dramatic increase in accessibility and prescribing of prescription drugs (19-21). As such, research and policy efforts focus heavily on understanding health care providers' prescribing behavior and identifying strategies to encourage providers to reduce their reliance on prescription drugs, particularly opioids. Early on, computerized Physician Order Entry (CPOE) systems were put in place to avoid adverse events by facilitating tracking of medications, supervising drug interactions, and reviewing laboratory reports $(22,23)$. Electronic health record (EHR) systems represent similar, but more technologically comprehensive approaches to assist providers and health care systems in tracking patients' prescriptions as well as their clinical visits, medical conditions, and other associated medical history to avoid prescribing deadly combinations of drugs and to enhance patient safety and the quality of health care $(24,25)$. Programs, such as PharmaNet, were developed to integrate multiple providers and health systems to reduce the improper prescribing of opioids and benzodiazepines (CNS depressant) by centralizing all prescriptions in one networked information system that contains live, updated data on patients' medications (26).

State policymakers also have launched prescription drug monitoring programs (PDMPs) to document and monitor the use of Schedule II - V narcotics $(1,7,27)$. The long-term goal of these programs is to reduce prescription drug abuse and identify instances of potential abuse (1). Data from PDMPs have been used primarily to monitor the dispensing of opioids, CNS depressants, and stimulants (27); document prescribing patterns (28); and identify potential cases of "doctor shopping" as well as problematic prescribing as part of law enforcement investigations (29). Studies of the effectiveness of PDMPs in reducing prescription drug abuse and improper prescribing are mixed $(1,27,29)$; however, many of these systems are still relatively new and in development.

While there have been significant policy changes in recent years pertaining to the oversight and regulation of prescribing practices, there has been little systematic research on prescribers' and dispensers' attitudes regarding community prescription drug misuse and abuse. Prior studies have documented that health care providers hold generally positive attitudes about the clinical acceptability and utility of pain medication. One survey, for example, found that approximately twothirds of prescribers had generally favorable attitudes about prescribing long-acting opioids to non-terminal pain patients because they believed that these medications can improve patients' overall quality of life (30). Support, however, varies depending on the providers' clinical role and specialty, with pharmacists and advanced practice nurses expressing more concern about the potential of overprescribing pain medication (31).

Unfortunately, little is known about health care providers' views of the prescription drug abuse epidemic, and how their views are reflected in their practices. In order to improve scientific understanding of the policy landscape surrounding public health efforts to address the epidemic, we utilized data from a large 
survey of different types of licensed health care providers to document their general level of concern regarding prescription drug abuse in their communities. The survey asked whether these attitudes are influential in individual providers' self-reported changes in their prescribing and/or dispensing practices.

\section{Methods}

This study is based on a voluntary, online survey of licensed health care providers conducted in 2013 in Indiana as part of a state-wide evaluation of the state's prescription drug monitoring program. The survey tool asked respondents how concerned they are about the prescription drug epidemic. Variation in the level of concern is examined using ordinary least squares (OLS) regression and information about the respondents' demographic background as well as their clinical practice and experience.

The survey instrument was developed by the first and third author collaboratively with Indiana Professional Licensing Agency (IPLA) staff and key leaders of Indiana's state-wide Prescription Drug Abuse Prevention Taskforce. Invitations to participate were distributed electronically by the IPLA to all 38,333 health care providers licensed to practice in Indiana in 2013. In addition to questions regarding the respondents' demographic background and characteristics of their clinical practice, providers were asked: "How concerned are you about prescription drug abuse in your community?" Responses included "extremely concerned," "moderately concerned," "slightly concerned," and "not concerned at all." In the multivariate analyses, responses were coded so that higher values indicated higher levels of concern. Respondents also were asked whether they prescribed (only physicians, NPs/PAs, and dentists) or dispensed controlled substances in the past 12 months and, if so, whether they had changed their prescribing/dispensing practices in the past year. If they had made changes, they were asked to indicate whether they were prescribing and/or dispensing "far more," "more," "fewer," or "far fewer" controlled substances. For this analysis, we collapsed those who indicated prescribing or dispensing fewer or far fewer (coded 1) and compared them with those who reported no changes or who increased their prescribing or dispensing of controlled substances (coded 0 ).

The focal independent variables were constructed based on responses to the questions regarding the respondents' demographic background and clinical work experience. Specifically, we included the following demographic measures: gender $(0=$ men; $1=$ women), age (in years, estimated based on the self-reported birth year); and race/ethnicity ( $0=$ white; $1=$ non-white). In terms of clinical background, we constructed indicators of the respondents' primary practice setting (coded as a series of dummies indicating whether the respondent worked in an outpatient, inpatient, emergency room/ urgent care, or other setting [the reference category]); years in practice; whether they practiced in a rural or urban area (based on U.S. Census Bureau scale that classifies Indiana counties from $1=$ most urban to $8=$ most rural); and, the percentage of patients in the respondents' practice they believe abuse prescription drugs. Additionally, to control more objectively for community prescription drug abuse burden, we included the per capita rate of scheduled prescriptions dispensed in the county where the respondent practiced, using data from Indiana's prescription drug monitoring program (32). Table 1 provides the frequency distributions for the independent variables.

IBM SPSS version 21.0 was used to prepare the data and complete all analyses. In addition to applying frequencies and cross-tabs to evaluate our basic research questions, we used multivariate OLS regression techniques to detect differences in the overall level of concern based on their demographic and clinical background. Logistic regression methods were used to examine the importance of concern on respondentreported recent changes in prescribing/dispensing practices while controlling for the focal background characteristics. Because age and years in clinical practice were highly correlated, only age was included in the multivariate analyses to avoid concerns with multicollinearity. The rate of missing data was relatively low on the independent variables $(<3-6 \%)$; as such, we substituted the mean (or referent value for dummy variables) when respondents did not provide valid responses. However, respondents who did not answer the focal dependent questions regarding concern and/ or prescribing practices were dropped from the analysis, thus 248 respondents were not included in our regression analysis.

\section{Results}

A total of 5,994 usable surveys were completed for a response rate of $15.6 \%$. The present analysis focuses on the 5,846 licensed health care professionals holding licenses in 4 major provider groups: physicians (MDs and DOs; $N=2,444$ ), mid-level providers (i.e., nurse practitioners and physician assistants or NPs/PAs; $\mathrm{N}=$ $1,067)$, dentists $(N=753)$, and pharmacists $(N=1,582)$ (Table 1). The discrepancy between total survey respon- 
Pain Physician: January 2016; 19:E197-E208

Table 1. Demographic, practice setting, and clinical experience of licensed prescribers and dispensers by provider type and for the total sample $(N=5,846)$.

\begin{tabular}{|c|c|c|c|c|c|c|c|c|c|c|}
\hline \multirow[b]{2}{*}{ Characteristic } & \multicolumn{2}{|c|}{$\begin{array}{c}\text { Physicians (MDs, } \\
\text { DOs, and DPMs) } \\
(\mathrm{N}=\mathbf{2 , 4 4 4 )}\end{array}$} & \multicolumn{2}{|c|}{$\begin{array}{c}\text { Nurse Practitioners } \\
\text { (NPs) and Physician } \\
\text { Assistants (PAs) }(\mathrm{N}= \\
\mathbf{1 , 0 6 7 )}\end{array}$} & \multicolumn{2}{|c|}{$\begin{array}{l}\text { Dentists } \\
(\mathrm{N}=753)\end{array}$} & \multicolumn{2}{|c|}{$\begin{array}{c}\text { Pharmacists } \\
(\mathrm{N}=\mathbf{1 , 5 8 2})\end{array}$} & \multicolumn{2}{|c|}{$\begin{array}{c}\text { Total } \\
\text { Sample } \\
(\mathrm{N}=\mathbf{5 , 8 4 6})\end{array}$} \\
\hline & $\mathbf{N}$ & $\%$ & $\mathbf{N}$ & $\%$ & $\mathbf{N}$ & $\%$ & $\mathbf{N}$ & $\%$ & $\mathbf{N}$ & $\%$ \\
\hline \multicolumn{11}{|l|}{ Gender $\left(\mathrm{X}^{2}=1,270.8, P<.001\right)$} \\
\hline Women & 683 & 28.8 & 919 & 88.9 & 155 & 21.4 & 833 & 54.4 & 2,590 & 45.7 \\
\hline \multicolumn{11}{|l|}{ Age $\left(\mathrm{X}^{2}=279.9, P<.001\right)$} \\
\hline 35 or younger & 241 & 10.3 & 174 & 17.0 & 81 & 11.2 & 401 & 26.4 & 897 & 16.0 \\
\hline $36-45$ & 464 & 19.9 & 269 & 26.2 & 123 & 17.0 & 315 & 20.7 & 1,171 & 20.9 \\
\hline $45-55$ & 606 & 25.9 & 304 & 29.7 & 192 & 26.6 & 328 & 21.6 & 1,430 & 25.5 \\
\hline 56 or older & 1,026 & 43.9 & 278 & 27.1 & 327 & 45.2 & 475 & 31.3 & 2,106 & 37.6 \\
\hline \multicolumn{11}{|l|}{ Race/Ethnicity $\left(\mathrm{X}^{2}=180.4, P<.001\right)$} \\
\hline Asian & 205 & 8.7 & 6 & 0.6 & 18 & 2.5 & 48 & 3.2 & 277 & 4.9 \\
\hline Black/African American & 73 & 3.1 & 19 & 1.8 & 11 & 1.5 & 28 & 1.8 & 131 & 2.3 \\
\hline Latino & 33 & 1.4 & 14 & 1.3 & 8 & 1.1 & 9 & 0.6 & 64 & 1.1 \\
\hline White & 1,940 & 82.6 & 981 & 94.4 & 667 & 92.3 & 1,404 & 92.2 & 4,992 & 88.6 \\
\hline Other Race & 99 & 4.2 & 19 & 1.8 & 19 & 2.6 & 34 & 2.2 & 171 & 3.0 \\
\hline \multicolumn{11}{|c|}{ Primary Practice Setting $\left(\mathrm{X}^{2}=2,150.3, P<.001\right)$} \\
\hline Outpatient & 1,323 & 54.1 & 636 & 59.6 & 510 & 67.7 & 139 & 8.8 & 2,608 & 44.6 \\
\hline Inpatient & 460 & 18.8 & 155 & 14.5 & 0 & 0.0 & 349 & 22.1 & 964 & 16.5 \\
\hline ER/Urgent Care & 316 & 12.9 & 130 & 12.2 & 2 & 0.3 & 4 & 0.4 & 452 & 7.7 \\
\hline Other & 345 & 14.1 & 146 & 13.7 & 241 & 32.0 & 1,090 & 68.9 & 1,822 & 32.2 \\
\hline \multicolumn{11}{|l|}{ Years in Practice $\left(\mathrm{X}^{2}=827.0, P<.001\right)$} \\
\hline Less than 5 years & 299 & 12.2 & 354 & 33.2 & 53 & 7.0 & 234 & 15.3 & 940 & 16.4 \\
\hline 5-9 years & 286 & 11.7 & 216 & 20.2 & 67 & 8.9 & 200 & 13.1 & 769 & 13.4 \\
\hline $10-14$ years & 286 & 11.7 & 220 & 20.6 & 59 & 7.8 & 140 & 9.2 & 705 & 12.3 \\
\hline $15-19$ years & 326 & 13.3 & 164 & 15.4 & 76 & 10.1 & 151 & 9.9 & 657 & 11.5 \\
\hline $20-24$ years & 341 & 14 & 53 & 5.0 & 95 & 12.6 & 170 & 11.1 & 659 & 11.5 \\
\hline 25 or more years & 906 & 37.1 & 60 & 5.6 & 403 & 53.5 & 630 & 41.3 & 1,999 & 34.9 \\
\hline \multicolumn{11}{|c|}{ Primary Practice Location $\left(\mathrm{X}^{2}=52.2, P<.001\right)$} \\
\hline $\begin{array}{l}\text { Metro Area: } \\
1 \text { Million or More People }\end{array}$ & 1,140 & 46.6 & 512 & 48.0 & 347 & 46.1 & 745 & 53.0 & 2,744 & 51.0 \\
\hline $\begin{array}{l}\text { Metro Area: } \\
250,000 \text { to } 1 \text { Million People }\end{array}$ & 597 & 24.4 & 191 & 17.9 & 153 & 20.3 & 193 & 13.7 & 846 & 15.7 \\
\hline $\begin{array}{l}\text { Metro Area: } \\
\text { Fewer than } 250,000 \text { People }\end{array}$ & 368 & 15.1 & 203 & 19.0 & 115 & 15.3 & 229 & 16.3 & 915 & 17.0 \\
\hline $\begin{array}{l}\text { Non-metro/Adjacent to Metro: } \\
\text { 20,000 or More People }\end{array}$ & 65 & 2.7 & 51 & 4.8 & 24 & 3.2 & 54 & 3.8 & 194 & 3.6 \\
\hline $\begin{array}{l}\text { Non-metro/Not Adjacent to Metro: } \\
\text { 20,000 or More People }\end{array}$ & 63 & 2.6 & 19 & 1.8 & 13 & 1.7 & 39 & 2.8 & 134 & 2.5 \\
\hline $\begin{array}{l}\text { Non-metro/Adjacent to Metro: } \\
\text { Less than 20,000 People }\end{array}$ & 180 & 7.4 & 78 & 7.3 & 86 & 11.4 & 127 & 9.0 & 471 & 8.8 \\
\hline $\begin{array}{l}\text { Non-metro/Not Adjacent to Metro: } \\
\text { Less than } 20,000 \text { People }\end{array}$ & 31 & 1.3 & 13 & 1.2 & 15 & 2.0 & 19 & 1.4 & 78 & 1.4 \\
\hline
\end{tabular}


Table 1 (cont.). Demographic, practice setting, and clinical experience of licensed prescribers and dispensers by provider type and for the total sample $(N=5,846)$.

\begin{tabular}{|c|c|c|c|c|c|c|c|c|c|c|}
\hline \multirow[b]{2}{*}{ Characteristic } & \multicolumn{2}{|c|}{$\begin{array}{c}\text { Physicians (MDs, } \\
\text { DOs, and DPMs) } \\
(\mathrm{N}=\mathbf{2 , 4 4 4})\end{array}$} & \multicolumn{2}{|c|}{$\begin{array}{c}\text { Nurse Practitioners } \\
\text { (NPs) and Physician } \\
\text { Assistants (PAs) }(\mathrm{N}= \\
1,067)\end{array}$} & \multicolumn{2}{|c|}{$\begin{array}{c}\text { Dentists } \\
(\mathrm{N}=\mathbf{7 5 3})\end{array}$} & \multicolumn{2}{|c|}{$\begin{array}{l}\text { Pharmacists } \\
(\mathrm{N}=\mathbf{1 , 5 8 2})\end{array}$} & \multicolumn{2}{|c|}{$\begin{array}{c}\text { Total } \\
\text { Sample } \\
(N=\mathbf{5 , 8 4 6})\end{array}$} \\
\hline & $\mathbf{N}$ & $\%$ & $\mathbf{N}$ & $\%$ & $\mathbf{N}$ & $\%$ & $\mathbf{N}$ & $\%$ & $\mathbf{N}$ & $\%$ \\
\hline \multicolumn{11}{|c|}{ Estimated Percent of Own Patients Who Misuse/Abuse Prescription Drugs $\left(\mathrm{X}^{2}=613.33, P<.001\right)$} \\
\hline $0 \%$ & 285 & 12.2 & 81 & 7.8 & 99 & 13.5 & 75 & 4.9 & 540 & 9.6 \\
\hline $1-10 \%$ & 1,119 & 47.9 & 499 & 48.0 & 478 & 65.0 & 400 & 26.2 & 2,496 & 44.3 \\
\hline $11-20 \%$ & 385 & 16.5 & 149 & 14.3 & 80 & 10.9 & 318 & 20.8 & 932 & 16.5 \\
\hline $21-30 \%$ & 238 & 10.2 & 128 & 12.3 & 41 & 5.6 & 252 & 16.5 & 659 & 11.7 \\
\hline $31-50 \%$ & 196 & 8.4 & 101 & 9.7 & 26 & 3.5 & 269 & 17.6 & 592 & 10.5 \\
\hline $51 \%$ or more & 114 & 4.9 & 82 & 7.9 & 11 & 1.5 & 212 & 13.9 & 419 & 7.4 \\
\hline \multicolumn{11}{|c|}{ Per Capita County Rate of Scheduled Prescriptions Dispensed $\left(\mathrm{X}^{2}=26.8, P<.002\right)$} \\
\hline Less than 1.00 & 216 & 8.8 & 140 & 13.4 & 84 & 11.7 & 114 & 8.1 & 554 & 10.3 \\
\hline $1.00-1.49$ & 1,480 & 66.8 & 680 & 65.3 & 469 & 65.1 & 981 & 69.8 & 3,610 & 67.1 \\
\hline $1.50-1.99$ & 355 & 16.0 & 158 & 15.2 & 126 & 17.5 & 227 & 16.1 & 866 & 16.1 \\
\hline 2.00 or higher & 164 & 7.4 & 63 & 6.1 & 41 & 5.7 & 84 & 6.0 & 352 & 6.5 \\
\hline
\end{tabular}

Table 2. Community concern regarding prescription drug abuse by provider type and for the total sample $(N=5,598)$.

\begin{tabular}{|c|c|c|c|c|c|c|c|c|c|c|}
\hline & \multicolumn{2}{|c|}{$\begin{array}{c}\text { Physicians (MDs, } \\
\text { DOs, and DPMs) } \\
(\mathrm{N}=\mathbf{2 , 3 7 5})\end{array}$} & \multicolumn{2}{|c|}{$\begin{array}{c}\text { Nurse Practitioners (NPs) } \\
\text { and Physician Assistants } \\
(\text { PAs })(\mathrm{N}=1,041)\end{array}$} & \multicolumn{2}{|c|}{$\begin{array}{c}\text { Dentists } \\
(\mathrm{N}=\mathbf{7 4 0})\end{array}$} & \multicolumn{2}{|c|}{$\begin{array}{c}\text { Pharmacists } \\
(\mathrm{N}=1,542)\end{array}$} & \multicolumn{2}{|c|}{$\begin{array}{l}\text { Total Sample } \\
(\mathbf{N}=\mathbf{5 , 5 9 8})\end{array}$} \\
\hline & $\mathbf{N}$ & $\%$ & $\mathbf{N}$ & $\%$ & $\mathbf{N}$ & $\%$ & $\mathbf{N}$ & $\%$ & $\mathbf{N}$ & $\%$ \\
\hline Not Concerned At All & 44 & 1.8 & 17 & 1.6 & 14 & 1.9 & 16 & 1.0 & 91 & 1.6 \\
\hline Slightly Concerned & 353 & 14.4 & 143 & 13.4 & 188 & 25.0 & 146 & 9.5 & 722 & 12.7 \\
\hline Moderately Concerned & 945 & 38.7 & 425 & 39.8 & 321 & 42.6 & 586 & 38.0 & 2,277 & 40.0 \\
\hline Extremely Concerned & 1,102 & 45.1 & 482 & 45.2 & 230 & 30.5 & 794 & 51.5 & 2,608 & 45.8 \\
\hline
\end{tabular}

dents and the present study's sample is accounted for by 148 participants who did not provide their professional licensure; we dropped these individuals from the analysis. Of the respondents included, the majority identified as white (88.6\%) and with slightly more men $(54.3 \%)$ than women $(45.7 \%)$. The mean age was just over 50 (50.3), with a mean of almost 19 years (18.8) of medical practice. Over half of the respondents (53.9\%) felt that 0 to $10 \%$ of their patients misused or abused prescription medications. Given the response rate and questions about the generalizability of our sample, we compared the present sample to a survey of licensed providers at the time of licensure renewal/new application ( $N=40,006$; see Appendix I). Difference of proportion and mean tests resulted in significant differences across all comparisons, except the gender distribution among dentists.
Table 2 describes the overall level of concern for our 4 provider groups and the full sample. The majority $(85.8 \%)$ indicated that they were either "extremely" or "moderately" concerned about prescription drug abuse in their communities. However, there were significant differences across the health care provider categories, with pharmacists being the most concerned $(89.5 \%)$, followed by NPs/PAs $(85.0 \%)$, and physicians $(83.8 \%)$. While a majority of dentists were concerned (73.1\% indicated extremely or moderately so), a significantly larger minority of dentists stated they were only "slightly concerned" or "not concerned at all" (26.9\%), compared with the other 3 provider groups.

The OLS multivariate analyses, reported in Table 3, indicated further that the providers most likely to be more concerned were those who are women $(b=.051)$, older $(b=.006)$, and white 
Table 3. OLS regression analysis of prescribers/dispensers' concern about community prescription drug abuse with provider demographic, clinical, and practice characteristics $(N=5,846)$.

\begin{tabular}{|c|c|c|c|}
\hline & b & SE & $\mathbf{T}$ \\
\hline Constant & 2.326 & .065 & $35.872^{* * *}$ \\
\hline Gender (Female) & .051 & .021 & $2.396^{*}$ \\
\hline Age & .006 & .001 & $7.488^{* * *}$ \\
\hline Race (Nonwhite) & -.091 & .029 & $-3.078^{* *}$ \\
\hline \multicolumn{4}{|l|}{ Provider Type (Physician) } \\
\hline Nurse Practitioner (NP)/Physician Assistant (PA) & -.033 & .028 & -1.149 \\
\hline Dentist & -.202 & .030 & $-6.740^{* * *}$ \\
\hline Pharmacist & -.019 & .028 & -.673 \\
\hline \multicolumn{4}{|l|}{ Primary Practice Setting (Other) } \\
\hline Outpatient & .030 & .025 & 1.188 \\
\hline Hospital & -.038 & .029 & -1.296 \\
\hline Emergency Room & .003 & .041 & .803 \\
\hline Primary Practice Location (Rural-Urban) & .013 & .006 & $2.161^{*}$ \\
\hline Perceived Patient Misuse/Abuse of Prescription Drugs & .167 & .007 & $23.610^{* * *}$ \\
\hline Per Capita County Rate of Scheduled Prescriptions Dispensed & .081 & .014 & $5.897^{* * *}$ \\
\hline $\mathrm{F}$ & \multicolumn{3}{|c|}{$68.930^{\star * *}$} \\
\hline S.E.E. & \multicolumn{3}{|c|}{.691} \\
\hline $\mathrm{R} 2$ & \multicolumn{3}{|c|}{.124} \\
\hline
\end{tabular}

${ }^{*}=<.05,{ }^{* *}=<.01,{ }^{* *}=<.001$

(bnonwhite $=-.091)$. In terms of clinical experience, respondents who practiced in more rural settings $(b=$ .013) and counties with higher rates of per capita dispensation of scheduled prescriptions $(b=.081)$ were significantly more concerned. Providers who believed that larger percentages of their patients abused prescription drugs also indicated higher levels of concern $(b=.167)$.

Table 4 details the providers' answers to the prescribing and dispensing practices questions. The vast majority of the physicians, NPs/PAs, and dentists reported prescribing controlled substances in the past 12 months $(86.3 \%, 90.8 \%$, and $91.8 \%$, respectively). Only a minority indicated they had changed their prescribing practices in the past 12 months. Nearly half (47.2\%) of the NPs/PAs specified they changed their prescribing practices. In contrast, only about a third (35.8\%) of the physicians and even fewer dentists (19.7\%) reported having changed their prescribing practices. Of those who reported changing, approximately $90 \%$ of the sample indicated prescribing fewer controlled substances in the past year. While significantly fewer physicians, mid-level providers, and dentists dispensed controlled substances compared with the pharmacists, we observed a similar pattern in that approximately one third $(35.1 \%)$ reported changing their dispensing practices, with the majority $(83.5 \%)$ indicating they dispensed fewer scheduled prescriptions.

To better understand the relationship between the providers' level of concern and the likelihood of changing their prescribing or dispensing behavior, we used logistic regression. We focused on the likelihood of change because the overwhelming direction of change was toward prescribing/dispensing fewer controlled substances. The results are reported in Table 5 . Consistent with the findings reported in Table 4, the multivariate models suggest NPs/PAs were significantly more likely to have changed their recent prescribing and dispensing behavior compared with physicians (Odds ratio $[\mathrm{ORs}]=1.563$ and 1.829 , respectively). Dentists were significantly less likely to report having changed their prescribing or dispensing behavior (ORs $=.472$ and .419 , respectively). Individuals who were working in inpatient clinical settings also were less likely to indicate having changed their practices (ORs $=.525$ and .220 ). Higher levels of concern about community prescription drug abuse and perceiving more prescription drug abuse among their own patients were associated with 
Table 4. Changes in prescribing and dispensing practices in past 12 months by provider type and for the total sample $(N=5,846)$.

\begin{tabular}{|c|c|c|c|c|c|c|c|c|c|c|}
\hline & \multicolumn{2}{|c|}{$\begin{array}{c}\text { Physicians } \\
\text { (MDs, DOs, and } \\
\text { DPMs })(\mathbf{N}= \\
\text { 2,375) }\end{array}$} & \multicolumn{2}{|c|}{$\begin{array}{c}\text { Nurse Practitioners } \\
\text { (NPs) and Physician } \\
\text { Assistants (PAs) (N } \\
=1,041)\end{array}$} & \multicolumn{2}{|c|}{$\begin{array}{l}\text { Dentists } \\
(\mathrm{N}=\mathbf{7 4 0})\end{array}$} & \multicolumn{2}{|c|}{$\begin{array}{c}\text { Pharmacists } \\
(N=1,542)\end{array}$} & \multicolumn{2}{|c|}{$\begin{array}{c}\text { Total Sample } \\
(\mathrm{N}=\mathbf{5 , 8 4 6})\end{array}$} \\
\hline & $\mathbf{N}$ & $\%$ & $\mathbf{N}$ & $\%$ & $\mathbf{N}$ & $\%$ & $\mathbf{N}$ & $\%$ & $\mathbf{N}$ & $\%$ \\
\hline \multicolumn{11}{|l|}{ In the past 12 months: } \\
\hline $\begin{array}{l}\text { Prescribed Controlled Substances } \\
(\mathrm{X} 2=25.16, P<.001)\end{array}$ & 2,078 & 86.3 & 957 & 90.8 & 676 & 91.8 & - & - & 3,711 & 88.4 \\
\hline $\begin{array}{l}\text { Changed Prescribing Practices } \\
(\mathrm{X} 2=128.49, P<.001)\end{array}$ & 728 & 35.8 & 444 & 47.2 & 131 & 19.7 & - & - & 1,303 & 35.8 \\
\hline $\begin{array}{l}\text { Prescribed Fewer Controlled Substances } \\
(\mathrm{X} 2=9.82, P<.007)\end{array}$ & 663 & 92.7 & 384 & 88.5 & 120 & 96.0 & - & - & 1,167 & 91.6 \\
\hline $\begin{array}{l}\text { Dispensed Controlled Substances } \\
(\mathrm{X} 2=2504.63, P<.001)\end{array}$ & 466 & 19.4 & 174 & 16.5 & 109 & 14.8 & 1371 & 90.1 & 2,120 & 37.1 \\
\hline $\begin{array}{l}\text { Changed Dispensing Practices } \\
(\mathrm{X} 2=34.52, P<.001)\end{array}$ & 129 & 28.3 & 77 & 44.8 & 18 & 17.3 & 506 & 37.6 & 730 & 35.1 \\
\hline $\begin{array}{l}\text { Dispensed Fewer Controlled Substances } \\
(\mathrm{X} 2=26.8, P<.002)\end{array}$ & 112 & 89.6 & 68 & 94.4 & 14 & 82.4 & 398 & 80.4 & 592 & 83.5 \\
\hline
\end{tabular}

higher odds of changing both prescribing (OR $=1.310$ and 1.251, respectively) and dispensing behavior (OR = 1.264 and 1.147).

\section{Discussion}

The majority of the health care providers surveyed indicated they were very concerned about community prescription drug abuse. Our research, however, reveals that there is a minority of providers who are still relatively unconcerned about the epidemic, particularly among dentists. The comparative lack of concern among dentists contrasts with the American Dental Association's (ADA) policy regarding prescribing pain medication as well as recent assertions regarding dentists' role in curbing prescription drug misuse and abuse (33). The ADA policy states, "Dentists are encouraged to recognize their responsibility for ensuring that prescription pain medications are available to the patients who need them, for preventing these drugs from becoming a source of harm or abuse and for understanding the special issues in pain management for patients already opiate dependent" (34). Across responding health care provider groups, concern appears to be associated with the actual prevalence of controlled substances dispensed in communities as well as, and perhaps more important, the extent that abuse is observed first hand in clinical practice.

The high levels of support may help to explain the speed and relative ease with which most states have been able to implement PDMPs and expand state-level regulation of prescription medications over the last decade. The implementation of these programs, and the associated regulations, could easily be perceived by health care professionals as inappropriate state intrusions into the autonomous practice of medicine. While there is anecdotal evidence of providers who are disturbed by the expansion of government regulation in the health care arena $(35,36)$, the high levels of concern about the negative impact of prescription drug abuse on communities may, in part, explain the lack of resistance to these new policies and regulations from the health care provider community. Many PDMPs also have been designed to provide useful information back to prescribers and dispensers to help them improve the quality of their day-to-day clinical decision-making, which may be welcomed and seen as less threatening, even though in reality, they do expand government's oversight of clinical practice.

More important for public health intervention efforts, our research suggests that a number of health care providers already have voluntarily begun to change their prescribing and dispensing practices in ways that may be reducing the supply of scheduled prescriptions in communities. Our finding that concern about community prescription drug abuse is strongly associated with changes in practice underscore that public health officials should continue, and possibly expand, their efforts to raise awareness across the health care provider community. This may be particularly important within the oral health care system, which historically has not 
Table 5. Logistic regression analysis of providers' reports of changing prescribing and dispensing behavior in past 12 months by provider demographic and practice characteristics and providers' self-reported concern regarding prescription drug abuse.

\begin{tabular}{|c|c|c|}
\hline & Changed Prescribing Behavior & Changed Dispensing Behavior \\
\hline & $\mathbf{O R}$ & $\mathbf{O R}$ \\
\hline Gender (Female) & .985 & .957 \\
\hline Age & .996 & .994 \\
\hline Race (Nonwhite) & 1.060 & 1.143 \\
\hline \multicolumn{3}{|l|}{ Provider Type (Physician) } \\
\hline Nurse Practitioner (NP)/Physician Assistant (PA) & $1.563^{\star * *}$ & $1.829^{* *}$ \\
\hline Dentist & $.472^{* * *}$ & $.419^{* *}$ \\
\hline Pharmacist & -- & 1.276 \\
\hline \multicolumn{3}{|l|}{ Primary Practice Setting (Other) } \\
\hline Outpatient & 1.065 & 1.004 \\
\hline Hospital & $.525^{\star * *}$ & $.220^{* * *}$ \\
\hline Emergency Room & 1.079 & .748 \\
\hline Primary Practice Location (Rural-Urban) & $1.057^{*}$ & .995 \\
\hline Perceived Patient Misuse/Abuse of Prescription Drugs & $1.251^{\star * *}$ & $1.147^{* * *}$ \\
\hline Per Capita County Rate of Scheduled Prescriptions Dispensed & .981 & 1.033 \\
\hline Concern Regarding Community Prescription Drug Abuse & $1.310^{* * *}$ & $1.264^{* *}$ \\
\hline -2 Log Likelihood & 4440.609 & 2485.128 \\
\hline Overall X2 & $309.47^{* * *}$ & 208.122 \\
\hline Nagelkerke R2 & .112 & .131 \\
\hline
\end{tabular}

${ }^{*}=<.05,{ }^{* *}=<.01,{ }^{* *}=<.001$

been as closely integrated clinically or organizationally with the general health care system $(37,38)$. In doing so, public health leaders could facilitate positive change by helping more providers appreciate the public health impact of day-to-day clinical decision-making.

While there are potential gains to increasing prescribers' and dispensers' concern, our analyses also imply that such efforts alone will probably not be sufficient to drive the large-scale changes in prescribing or dispensing practices necessary to turn the tide on the expanding prescription drug epidemic. About a third of our respondents reported voluntarily changing their behavior, in part, because they simply are more concerned about what is happening in their local communities. In this regard, informational and educational campaigns targeting health care providers should be part of any comprehensive state plan. Public health leaders, however, also should consider other options to encourage a larger proportion of health care providers to exercise even more caution in prescribing and/or dispensing scheduled medications. Many states are exploring and piloting additional strategies, including requiring clinicians to consult PDMP data prior to writing a prescription. Furthermore, some states and health care institutions are offering professional continuing education on alternative pain management strategies (39) as well as free to low cost units on preventing abuse (see, for example, Boston University School of Medicine's www.opioidprescribing.com). Furthermore, professional associations are calling for more detailed guidelines when prescribing abused medications, especially in patients suffering chronic pain $(40,41)$. Finally, boosting continuing education that specifically addresses prescription drug misuse and abuse is in keeping with a number of professional organization's policies, e.g., American Medical Association and the American Dental Association $(34,42)$.

As with all studies, this research has important limitations. While it is a relatively large survey of health care providers, the study was voluntary and may not be generalizable to all health care providers in Indiana. Similarly, the study focused on Indiana, a medium-size Midwestern state with a higher burden of prescription drug abuse than many states (43), and the results may not be generalizable to health care providers in other parts of the country. Finally, the study relied on a single 
question to assess providers' concern and a subjective indicator of changes in recent clinical decision-making. Future research should explore providers' views more fully using a more representative sample and explore how these beliefs shape clinical decision-making using longitudinal medical record data.

\section{Conclusions}

The findings from this study suggest that more work can be done to encourage health care providers to take action to support public health efforts to reduce the scourge of prescription drug abuse in communities across the nation. While the majority of providers surveyed indicate they are concerned, significant pockets of health care professionals who are relatively unconcerned remain. Increasing providers' concern about the community impact of prescription drug abuse also appears to be an important factor in motivating them to take voluntary action to reduce the availability of scheduled prescription medications in the community. More generally, this research underscores the critical importance of engaging health care providers fully in public health efforts to reverse the course of the prescription drug epidemic.

\section{Acknowledgments}

\section{Disclosure}

Dr. Wright is the PI of the study, has full access to all the data in the study, and takes principal responsibility for the integrity of the data and the accuracy of the data analysis. Dr. Wright and Mr. Kooreman designed the study protocol. Dr. Wright, Ms. Reed, and Mr. Carnes managed the literature searches and summaries of previous related work and collaborated in the development of the first draft of the manuscript. Dr.
Wright provided revision for intellectual content and final approval of the manuscript.

\section{Conflict of Interest}

All authors have no conflicts of interest to report. None of the authors of the manuscript received any remuneration. Further, the authors have not received any reimbursement or honorarium in any other manner. The authors are not affiliated in any manner with the Indiana Professional Licensing Agency, which funded the overall study informing the present manuscript.

\section{Funding/Support}

The authors wish to disclose and thank the sponsor of the study. The study was conducted by Dr. Wright and Mr. Kooreman at the Center for Health Policy at the Indiana University Richard M Fairbanks School of Public Health at Indiana University-Purdue University Indianapolis (IUPUI). The study was sponsored by the Indiana Professional Licensing Agency (INSPECT Evaluation Grant \#A262-3-250-107). The sponsorship was limited to supplies and expenses. The sponsorship included payment for employees for designing the study, collecting data, and analysis of data. They had no influence or interference after the protocol was designed.

\section{Role of Sponsor}

The financial sponsor of this work had no role in the design and conduct of the study or the collection, management, analysis, and interpretation of the data. The sponsor also did not have a role in the preparation or review of the manuscript or the decision to submit. We also would like to thank the editorial board of Pain Physician for review and criticism in improving the manuscript. 
Pain Physician: January 2016; 19:E197-E208

Appendix A. Sample comparison.

\begin{tabular}{|c|c|c|c|c|c|c|c|c|c|c|c|}
\hline & & $\begin{array}{r}\text { Phys } \\
\text { (MDs, } \\
\text { DP }\end{array}$ & and & $\begin{array}{r}\text { Nurse } \\
\text { (NPs) } \\
\text { Assis }\end{array}$ & $\begin{array}{l}\text { tioners } \\
\text { ysician } \\
\text { (PAs) }\end{array}$ & De & & Pharn & acists & \multirow{2}{*}{\multicolumn{2}{|c|}{ Total Sample }} \\
\hline \multicolumn{2}{|c|}{ Source \& Characteristic } & $\mathbf{N}$ & $\%$ & $\mathbf{N}$ & $\%$ & $\mathbf{N}$ & $\%$ & $\mathbf{N}$ & $\%$ & & \\
\hline \multicolumn{2}{|l|}{ Present Study } & 2,444 & 41.8 & 1,067 & 18.3 & 753 & 12.9 & 1,582 & 27.0 & \multicolumn{2}{|c|}{$\mathrm{N}=5,846$} \\
\hline \multicolumn{2}{|c|}{ IPLA Application } & 20,941 & 56.9 & 961 & 2.6 & 4,354 & 11.8 & 10,559 & 28.7 & \multicolumn{2}{|c|}{$\mathrm{N}=36,815$} \\
\hline \multicolumn{2}{|c|}{$\begin{array}{l}\text { Difference of Proportion } \\
\text { Z-score ( } P \text {-value) }\end{array}$} & \multicolumn{2}{|c|}{$-21.5(\sim 0)^{*}$} & \multicolumn{2}{|c|}{$52.2(\sim 0)^{*}$} & \multicolumn{2}{|c|}{$2.3(0.02)^{*}$} & \multicolumn{2}{|c|}{$-2.6(0.01)^{\star}$} & & \\
\hline \multicolumn{12}{|l|}{ Present Study } \\
\hline \multicolumn{10}{|l|}{ Gender } & \multicolumn{2}{|c|}{$\mathrm{N}=5,666$} \\
\hline \multicolumn{2}{|l|}{ Women } & 683 & 28.8 & 919 & 88.9 & 155 & 21.4 & 833 & 54.4 & 2,590 & 45.7 \\
\hline \multicolumn{2}{|l|}{ Men } & 1692 & 71.2 & 115 & 11.1 & 570 & 78.6 & 699 & 45.6 & 3,076 & 54.3 \\
\hline \multicolumn{12}{|c|}{ IPLA Application } \\
\hline \multirow[t]{3}{*}{ Gender } & & & & & & & & & & $\mathrm{N}=3$ & 557 \\
\hline & Women & 5,594 & 27.2 & 4,738 & 89.2 & 891 & 24.9 & 4,792 & 59.4 & 16,015 & 42.6 \\
\hline & Men & 15,010 & 72.8 & 574 & 10.8 & 2,681 & 75.1 & 3,277 & 40.6 & 21,542 & 57.4 \\
\hline \multicolumn{2}{|c|}{$\begin{array}{l}\text { Difference of Proportion } \\
\text { Z-score }(P \text {-value })\end{array}$} & \multicolumn{2}{|c|}{$-5.7(\sim 0)^{\star}$} & \multicolumn{2}{|c|}{$7.5(\sim 0)^{*}$} & \multicolumn{2}{|c|}{$1.7(0.1)$} & \multicolumn{2}{|c|}{$4.0(\sim 0)^{\star}$} & & \\
\hline \multicolumn{12}{|l|}{ Present Study } \\
\hline \multicolumn{10}{|l|}{ Age } & \multicolumn{2}{|c|}{$\mathrm{N}=5,603$} \\
\hline \multicolumn{2}{|l|}{35 or younger } & 241 & 10.3 & 174 & 17.0 & 81 & 11.2 & 401 & 26.4 & 897 & 16.0 \\
\hline \multicolumn{2}{|l|}{$36-45$} & 464 & 19.9 & 269 & 26.2 & 123 & 17.0 & 315 & 20.7 & 1,171 & 20.9 \\
\hline \multicolumn{2}{|l|}{$46-55$} & 606 & 25.9 & 304 & 29.7 & 192 & 26.6 & 328 & 21.6 & 1,430 & 25.5 \\
\hline 56 or older & & 1,026 & 43.9 & 278 & 27.1 & 327 & 45.2 & 475 & 31.3 & 2,106 & 37.6 \\
\hline & & & & & & & & $-\mathrm{X}=$ & & $s=$ & \\
\hline IPLA Licensure & & & & & & & & & & & \\
\hline Age & & & & & & & & & & $\mathrm{N}=4$ & 006 \\
\hline 35 or younger & & 2,749 & 13.3 & 1,550 & 29.2 & 736 & 20.6 & 3,361 & 32.1 & 8,396 & 21.0 \\
\hline $36-45$ & & 5,491 & 26.6 & 1,438 & 27.1 & 740 & 20.7 & 2,655 & 25.4 & 10,324 & 25.8 \\
\hline $46-55$ & & 5,490 & 26.6 & 1,312 & 24.7 & 802 & 22.4 & 2,127 & 20.3 & 9,731 & 24.3 \\
\hline 56 or older & & 6,924 & 33.5 & 1,004 & 18.9 & 1,302 & 36.4 & 2,325 & 22.2 & 11,555 & 28.9 \\
\hline & & & & & & & & $\mu=$ & & $\sigma=$ & \\
\hline $\begin{array}{l}\text { Difference of } \mathrm{Me} \\
\text { T-score }(P \text {-value }\end{array}$ & & & & & & & & & & 9.8 & \\
\hline
\end{tabular}




\section{References}

1. Brady JE, Wunsch $H$, Dimaggio $C$, Lang $\mathrm{BH}$, Giglio J, Li G. Prescription drug monitoring and dispensing of prescription opioids. Public Health Reports 2014; 129:139-147.

2. FDA study finds spike in ADHD medication use in children. Brown University Child \& Adolescent Psychopharmacology Update 2012; 14:1-4.

3. Jann M, Kennedy WK, Lopez G. Benzodiazepines: A major component in unintentional prescription drug overdoses with opioid analgesics. Journal of Pharmacy Practice 2014; 27:5-16.

4. McLellan AT, Turner B. Prescription opioids, overdose deaths, and physician responsibility. JAMA 2008; 300:2672-2673.

5. Straus MM, Ghitza UE, Tai B. Preventing deaths from rising opioid overdose in the US -- the promise of naloxone antidote in community-based naloxone take-home programs. Substance Abuse \& Rehabilitation 2013; 4:65-72.

6. Paulozzi LJ, Kilbourne EM, Desai HA. Prescription drug monitoring programs and death rates from drug overdose. Pain Medicine 2011; 12:747-754.

7. Manchikanti L. National drug control policy and prescription drug abuse: Facts and fallacies. Pain Physician 2007; 10:399424.

8. Saha TD, Compton WM, Chou SP, Smith $S$, Ruan W, Huang B, Pickering RP, Grant $B F$. Analyses related to the development of DSM-5 criteria for substance use related disorders: 1 . Toward amphetamine, cocaine and prescription drug use disorder continua using item response theory. Drug and Alcohol Dependence 2012; 122:38-46.

9. Hernandez S, Nelson L. Prescription drug abuse: Insight into the epidemic. Clinical Pharmacology \& Therapeutics 2010; 88:307-317.

10. Garnier-Dykstra LM, Caldeira KM, Vincent KB, O'Grady KE, Arria AM. Nonmedical use of prescription stimulants during college: Four-year trends in exposure opportunity, use, motives, and sources. Journal of American College Health 2012; 60:226-234.

11. Weyandt LL, Marraccini ME, Gudmundsdottir BG, Zavras BM, Turcotte KD, Munro BA, Amoroso AJ. Misuse of prescription stimulants among college students: A review of the literature and implications for morphological and cognitive effects on brain functioning. Ex- perimental and Clinical Psychopharmacology 2013; 21:385-407.

12. David C, Passmore AP, Fullerton KJ, Beringer TR, Gilmore DH, Crawford VL, McCaffrey PM, Montgomery A. Factors influencing prescription of CNS medications in different elderly populations. Pharmacoepidemiology \& Drug Safety 2003; 12:383-387.

13. Fisher J, Sanyal C, Frail D, Sketris I. The intended and unintended consequences of benzodiazepine monitoring programmes: A review of the literature. Journal of Clinical Pharmacy \& Therapeutics. 2012; 37:7-21.

14. McCabe SE, Cranford JA, Delva J, McPherson MD, Boyd C). Race/ethnicity and gender differences in drug use and abuse among college students. Journal of Ethnicity in Substance Abuse 2007; 6:75-95.

15. Keyes KM, Cerdá M, Brady JE, Havens $J R$, Galea S. Understanding the rural-urban differences in nonmedical prescription opioid use and abuse in the United States. American Journal of Public Health 2014; 104:e52-e59.

16. Young AM, Havens JR, Leukefeld CG. A comparison of rural and urban nonmedical prescription opioid users' lifetime and recent drug use. American Journal of Drug \& Alcohol Abuse 2012; 38:220-227.

17. Birnbaum HG, White AG, Schiller $M$, Waldman T, Cleveland JM, Roland CL. Societal costs of prescription opioid abuse, dependence, and misuse in the United States. Pain Medicine 2011; 12:657667.

18. National Center on Addiction and Substance Abuse at Columbia University. National Survey of American Attitudes on Substance Abuse XVII: Teens New York, NY; 2014. June 21, 2015. www.casacolumbia.org/addiction-research/reports/national-survey-american-attitudes-substance-abuse-teens-2012.

19. Compton WM, Volkow ND. Major increases in opioid analgestic abuse in the United States: Concerns and strategies. Drug and Alcohol Dependence 2006; 81:103-107.

20. Maxwell JC. The prescription drug epidemic in the United States: A perfect storm. Drug \& Alcohol Review 2011; 30:264-270.

21. Manchikanti L, Singh A. Therapeutic opioids: A ten-year perspective on the complexities and complications of the escalating use, abuse, and nonmedical use of opioids. Pain Physician 2008; 11:S63-S88.

22. Ammenwerth $E$, Schnell-Inderst $P$, Machan C, Siebert U. The effect of electronic prescribing on medication errors and adverse drug events: A systematic review. Journal of the American Medical Informatics Association 2008; 15:585-600.

23. Kuperman GJ, Bobb A, Payne TH, Avery AJ, Gandhi TK, Burns G, Classen DC, Bates DW. Medication-related clinical decision support in computerized provider order entry systems: A review. Journal of the American Medical Informatics Association 2007; 14:29-40.

24. Simon SR, Kaushal R, Cleary PD, Jenter CA, Volk LA, Poon EG, Orav EJ, Lo HG, Williams DH, Bates DW. Correlates of electronic health record adoption in office practices: A statewide survey. Journal of the American Medical Informatics Association 2007; 14:110-117.

25. Lapane KL, Waring ME, Schneider KL, Dubé C, Quilliam BJ. A mixed method study of the merits of e-prescribing drug alerts in primary care. Journal of General Internal Medicine 2008; 23:442446.

26. Dormuth CR, Miller TA, Huang A, Mamdani MM, Juurlink DN. Effect of a centralized prescription network on inappropriate prescriptions for opioid analgesics and benzodiazepines. CMA] 2012; 184:E852-E856.

27. Katz N, Panas L, Kim M, Audet AD, Bilansky A, Eadie J, Kreiner P, Paillard FC, Thomas C, Carrow G. Usefulness of prescription monitoring programs for surveillance-analysis of Schedule II opioid prescription data in Massachusetts, 1996-2006. Pharmacoepidemiology and Drug Safety 2010; 19:115-123.

28. Reifler LM, Droz D, Bailey JE, Schnoll SH, Fant R, Dart RC, Bartelson BB. Do prescription monitoring programs impact state trends in opioid abuse/misuse? Pain Medicine 2012; 13:434-442.

29. Wilsey BL, Fishman SM, Gilson AM, Casamalhuapa C, Baxi H, Lin TC, Li CS. An analysis of the number of multiple prescribers for opioids utilizing data from the California Prescription Monitoring Program. Pharmacoepidemiology and Drug Safety 2011; 20:1262-1268.

30. Nwokeji ED, Rascati KL, Brown CM, Eisenberg A. Influences of attitudes on family physicians' willingness to prescribe long-acting opioid analgesics for patients with chronic nonmalignant 
pain. Clinical Therapeutics 2007; 29:2589602.

31. Ying $X$, Schulman-Green D, Czaplinski C, Harris D, McCorkle R. Pain Attitudes and knowledge among RNs, pharmacists, and physicians on an impatient oncology service. Clinical Journal of Oncology Nursing 2007; 11:687-695.

32. Wright ER, Greene MS, Kooreman HE, Williams MJ, Watson DP. The consumption and consequences of alcohol, tobacco, and drugs in Indiana: A state epidemiological profile, 2012. May 15 , 2015. www.healthpolicy.iupui.edu/PubsPDFs $/ 2012 \% 20$ State\%20Epidemiological\%2oProfile.pdf.

33. Denisco RC, Kenna GA, O’Neil MG, Kulich RJ, Moore PA, Kane WT, Mehta NR, Hersh EV, Katz NP. Prevention of prescription opioid abuse: The role of the dentist. The Journal of the American Dental Association 2011; 142:800-810.

34. American Dental Association. Statement on the use of opioids in the treatment of dental pain. June 21, 2015. www.ada.org/ en/about-the-ada/ada-positions-policies-and-statements/statement-on-opioids-dental-pain.

35. Hood G. Weekend Call: Medscape. May 5, 2014. http://boards.medscape.com/fo rums/?128@@.2a339438!comment=1.

36. Hood G. Weekend Call: Medscape. May 5, 2014. http://boards.medscape.com/fo rums/?128@@.2a5be541!comment=1.

37. Mertz E, O'Neil E. The growing chal- lenge of providing oral health care services to all Americans. Health Affairs 2002; 21:65-77.

38. Mouradian WE, Wehr E, Crall JJ. Disparities in children's oral health and access to dental care. JAMA 2000; 284:26252631.

39. McLeod J, Murphy K. Reducing prescription drug abuse: Lessons learned from an NGA Policy Academy. Washington, DC: National Governors Association; 2014. June 28, 2014 www.nga.org/ files/live/sites/NGA/files/pdf/2014/1402 ReducingPrescriptionDrugAbuse-Paper. pdf.

40. Manchikanti L, Abdi S, Atluri S, Balog CC, Benyamin RM, Boswell MV, Brown $\mathrm{KR}$, Bruel BM, Bryce DA, Burks PA, Burton AW, Calodney AK, Caraway DL, Cash, KA, Christo PJ, Damron KS, Datta $S$, Deer TR, Diwan S, Eriator I, Falco FJ, Fellows B, Geffert S, Gharibo CG, Glaser SE, Grider JS, Hameed H, Hameed $M$, Hansen $H$, Harned ME, Hayek SM, Helm S, Hirsch JA, Janata JW, Kaye AD, Kaye AM, Kloth DS, Koyyalagunta D, Lee M, Malla Y, Manchikanti KN, McManus CD, Pampati V, Parr AT, Pasupuleti R, Patel VB, Sehgal N, Silverman SM, Singh V, Smith HS, Snook LT, Solanki DR, Tracy DH, Vallejo R, Wargo BW. American Society of Interventional Pain Physicians (ASIPP) guidelines for responsible opioid prescribing in chronic non-cancer pain: Part I--evidence assessment. Pain Physician 2012; 15:S1-S65.
41. Manchikanti L, Abdi S, Atluri S, Balog CC, Benyamin RM, Boswell MV, Brown $K R$, Bruel BM, Bryce DA, Burks PA, Burton AW, Calodney AK, Caraway DL, Cash, KA, Christo PJ, Damron KS, Datta $S$, Deer TR, Diwan S, Eriator I, Falco FJ, Fellows B, Geffert S, Gharibo CG, Glaser SE, Grider JS, Hameed H, Hameed $M$, Hansen $H$, Harned ME, Hayek SM, Helm S, Hirsch JA, Janata JW, Kaye AD, Kaye AM, Kloth DS, Koyyalagunta D, Lee M, Malla Y, Manchikanti KN, McManus CD, Pampati V, Parr AT, Pasupuleti R, Patel VB, Sehgal N, Silverman SM, Singh V, Smith HS, Snook LT, Solanki DR, Tracy DH, Vallejo R, Wargo BW. American Society of Interventional Pain Physicians (ASIPP) guidelines for responsible opioid prescribing in chronic non-cancer pain: Part II--guidance. Pain Physician 2012; 15:S67-S116.

42. American Medical Association. AMA at forefront of efforts to combat prescription drug abuse, overdose AMAWIRE: American Medical Association; 2013. May 5, 2015. www.ama-assn.org/ams/ pub/amawire/2013-july-10/2013-july10-general_newsı.shtml.

43. Wright ER, Kooreman HE, Greene MS, Chambers RA, Banerjee A, Wilson J. The iatrogenic epidemic of prescription drug abuse: County-level determinants of opioid availability and abuse. Drug and Alcohol Dependence 2014; 138:209215 . 